\title{
CONSIDERAÇÕES SOBRE A DIMENSÃO HISTÓRICA NA FORMAÇÃO DE PROFESSORES DE MATEMÁTICA
}

\author{
CONSIDERATIONS FOR HISTORICAL DIMENSION IN TEACHER OF \\ MATHEMATICS
}

\section{RESUMO}

O objetivo deste texto, que surge do estudo em uma disciplina no Doutorado em Educação em Ciências e Matemática, é fazer a análise crítica do artigo "Quem somos nós, professores de matemática?", do prof. Wagner Valente, publicado em 2008, no Cad. Cedes, Campinas. O autor, na busca por responder à questão que serve de título do artigo, sustenta-se no argumento de que considerar a dimensão histórica na formação de professores de matemática pode contribuir para a produção de novos saberes e a criação de novas práticas que possibilitem aos professores desenvolver seu trabalho pedagógico com melhor qualidade. Com esse propósito, desenvolve o que chama de uma genealogia profissional do professor de matemática, apoiando-se em fontes históricas. Para a análise crítica do artigo, procedeu-se a um estudo para compreender as relações lógicas entre os elementos constitutivos do conhecimento produzido pelo autor. Para tanto, utilizou-se o "esquema paradigmático" proposto por Gamboa (2007), que visa a permitir reconstituir a lógica do texto no trajeto percorrido pela investigação, que vai da Pergunta $(\mathrm{P})$ até a Resposta $(\mathrm{R})$. O trabalho está organizado em três momentos, além das considerações iniciais e finais. No primeiro, faz-se uma abordagem sobre a dimensão histórica na formação de professores de matemática; no segundo, sintetiza-se o artigo analisado; no terceiro, analisa-se criticamente o artigo. A análise mostra que a dimensão histórica na formação de professores de matemática pode remeter a um campo complexo, permeado de intencionalidades e significados que possibilitem uma compreensão mais ampla daquela formação.

Palavras-chave: Formação de professores de matemática; História da educação matemática; Análise crítica.

\begin{abstract}
The purpose of this text, which arises from the study in a discipline in Doctorate in Education in Science and Mathematics, is to make a critical analysis of the article "Who are we, math teachers?", the prof. Wagner Valente, published in 2008, Cad. Cedes, Campinas. The author, in seeking to answer the question that serves as the title of the article argues the argument to

${ }^{1}$ Doutoranda do Programa de Pós-Graduação em Educação em Ciências e Matemática da Rede Amazônica de Educação em Ciências e Matemática (REAMEC) na Universidade do Estado do Amazonas (UEA), Manaus, AM - Brasil, e-mail: marinsrosa@yahoo.com.br.

${ }^{2}$ Doutor em Educação. Professor do Programa de Pós-Graduação em Educação em Ciências e Matemática da Rede Amazônica de Educação em Ciências e Matemática (REAMEC) na Universidade do Estado do Amazonas (UEA), Manaus, AM - Brasil, e-mail: amarildo.gonzaga@yahoo.com.br.
\end{abstract}




\section{REVISTA REAMEC \\ Revista da Rede Amazônica de Educação \\ em Ciências e Matemática}

consider the historical dimension in the training of mathematics teachers can contribute to the production of new knowledge and the creation of new practices that enable teachers develop their pedagogical work with better quality. For this purpose, it develops what it calls a genealogy professional math teacher, relying on historical sources. For a critical analysis of the article, we proceeded to a study to understand the logical relationships between the elements of the knowledge produced by the author. For this, we used the "paradigmatic scheme" proposed by Gamboa (2007), which aims to allow reconstruct the logic of the text on the path traversed by the research, which will question the $(\mathrm{P})$ to the response $(\mathrm{R})$. The paper is organized in three stages, in addition to the initial and final considerations. In the first, it is an approach to the historical dimension in the training of mathematics teachers, in the second sums up the article analyzed, in the third, we analyze critically the article. The analysis shows that the historical dimension in the training of mathematics teachers may refer to a complex field, permeate intentions and meanings that enable a broader understanding of that training.

Keywords: Formation of teachers of mathematics; History of mathematics education; Critical analysis.

\section{CONSIDERAÇÕES INICIAIS}

Este estudo surge do desenvolvimento de uma disciplina cursada, em 2012, no doutorado em Educação em Ciências e Matemática, a partir da proposição de análise crítica de um dos textos referentes à temática tratada na disciplina. Procurando manter coerência com nosso campo de estudo, que é a formação de professores, buscamos realizar a análise crítica de um texto que caminhasse nesse campo. Outro aspecto importante para a escolha do texto foi o fato de considerarmos a dimensão histórica como necessária a uma compreensão mais ampla desse campo de estudo.

Em face do exposto, ao nos depararmos com os estudos realizados por Valente em 2008, 2010, 2011, dentre outros, sobre a dimensão histórica na formação de professores de matemática, consideramos que poderiam ser referência para muitas pesquisas, inclusive a nossa, no campo da formação de professores de modo geral, pela perspectiva epistemológica dada àquela dimensão como formadora de professores, pois no centro das proposições encontra-se, particularmente, a necessidade de considerar o passado profissional (prática pedagógica) como possibilidade para melhor compreensão do presente (trabalho docente) ${ }^{3}$.

Dos estudos de Valente mencionados, optamos pelo primeiro texto (VALENTE, 2008) porque nos pareceu central para compreender o pensamento do autor sobre a importância da dimensão histórica na formação de professores de matemática, ainda que este

${ }^{3}$ De acordo com Brzezinsk e Garrido (2007), a expressão trabalho docente, mais abrangente, surge para substituir prática pedagógica, utilizada no período de 1990 a 1996. 


\section{REVISTA REAMEC}

Revista da Rede Amazônica de Educação

em Ciências e Matemática

texto tenha nos parecido trazer uma discussão introdutória sobre aquela dimensão, enquanto os dois últimos textos (VALENTE, 2010, 2011) uma discussão mais aprofundada.

No texto escolhido para análise, o autor, na busca por responder à questão que lhe serve de título - "Quem somos nós professores de matemática" -, sustenta-se no argumento Página | 6 de que considerar a dimensão histórica na formação de professores de matemática pode contribuir para a produção de novos saberes e a criação de novas práticas que deem aos professores a possibilidade de desenvolver seu trabalho pedagógico com melhor qualidade. Com esse propósito, desenvolve o que chama de uma genealogia profissional do professor de matemática, apoiando-se em fontes históricas.

Para a análise crítica, desenvolvemos um estudo teórico para compreender as relações lógicas entre os elementos constitutivos do conhecimento produzido pelo autor, utilizando-se, para tanto, do "esquema paradigmático" proposto por Gamboa (2007), que tem por objetivo permitir uma reconstituição da lógica do texto no trajeto percorrido pelo autor para realizar a investigação, que vai da Pergunta $(\mathrm{P})$ até a Resposta (R).

Com essa perspectiva, organizamos o trabalho em três momentos, além das considerações iniciais e finais. No primeiro momento, fazemos uma breve abordagem sobre a dimensão histórica na formação de professores de matemática; no segundo, procedemos à síntese do artigo analisado; no terceiro, analisamos criticamente o artigo.

\section{SITUANDO A DIMENSÃo HISTÓRICA NA FORMAÇÃO DO PROFESSOR DE MATEMÁTICA}

Antes de apresentarmos a síntese do artigo em análise, consideramos oportuno situar a dimensão histórica na formação de professores de matemática, tema central do artigo, visto que se insere em um contexto amplo que vem discutindo essa dimensão como possibilitadora de uma nova epistemologia na formação de professores em âmbito geral e, em âmbito específico, na formação de professores de matemática. Além do mais, isso pode ampliar nossa visão para uma análise mais densa do artigo.

De modo geral, seja na vida pessoal, seja profissional, há interesse das pessoas em conhecer sua história. No que diz respeito à profissão professor, tem-se na história da própria profissão e das disciplinas escolares uma relação indissociável. Assim, tem-se "História da 


\section{REVISTA REAMEC}

Revista da Rede Amazônica de Educação

em Ciências e Matemática

Física", "História da Química", "História da Biologia”, "História da Matemática”, etc. Nesse caso, o conhecimento dessas "Histórias" passa, muito particularmente, pelo conhecimento da própria profissão de professor na disciplina. Nesse aspecto, no que diz respeito à matemática, a importância conhecimento da História da Matemática parece ser indiscutível na formação de professores de matemática.

No que diz respeito à formação de professores de matemática, a História da Matemática pode ser vista como proposta metodológica para conhecer a gênese dos conceitos e métodos da disciplina matemática desenvolvida ao longo dos anos, o que poderá proporcionar uma visão dinâmica de sua evolução (GROENWALD et al., 2004).

Não obstante, Valente (2010) e Souto (2010) fazem distinção, na formação de professores de matemática, entre pensar a História da Matemática e pensar a história da educação matemática ${ }^{4}$, pois enquanto a primeira preocupa-se em apontar a importância de o professor conhecer como o conhecimento matemático foi e vem sendo produzido, a segunda foca suas preocupações na necessidade de o professor conhecer práticas pedagógicas de professores de matemática de outros tempos como possibilidade para compreender em que aspectos essas práticas reelaboradas encontram-se presentes na sua prática pedagógica cotidiana.

No estudo realizado sobre os trabalhos no campo da História na Educação Matemática ${ }^{5}$, realizados no Brasil nos últimos cinco anos, Souto (2010) avaliou estudos que fazem reflexões teóricas ou relatam experiências sobre o possível apoio da História em situações de ensino-aprendizagem da Matemática, analisando os interesses, direções e focos das pesquisas no campo considerado. Constatou que a grande maioria dos trabalhos contempla temas específicos de História da Matemática e que o número de trabalhos sobre História na Educação Matemática ainda é pouco expressivo. Conclui que a defesa das potencialidades didáticas da História, há muito veiculada nos discursos de professores, autores

\footnotetext{
${ }^{4}$ Souto (2010) usa a expressão "História da Educação Matemática", sempre em maiúscula, com referência ao campo de pesquisa instituído a partir da década de 80 . Valente (2010) utiliza essa expressão em maiúscula com o mesmo sentido, mas em minúscula quando se refere ao processo de ensino e aprendizagem da matemática, próprio da história da escola. Nessa perspectiva, o autor situa a história da educação matemática como área de pesquisa no interior da Educação Matemática - assim também procedemos.

${ }^{5}$ Souto (2010) diz que utiliza a expressão História na Educação Matemática (e não História da Educação Matemática) para se referir aos trabalhos que buscam apoio da História para tratar da Matemática em situações de ensino e aprendizagem.
} 


\title{
REVISTA REAMEC
}

Revista da Rede Amazônica de Educação

em Ciências e Matemática

de livros didáticos e gestores da educação pública, ainda não se materializou em experiências ou investigações que promovam efetivamente essa articulação.

Sem a intenção de buscar justificativas para os resultados da pesquisa antes mencionada, temos a impressão de que um dos fatores que podem ser favoráveis aos Página |8 resultados encontrados se deve, particularmente, ao tratamento da perspectiva histórica na formação de professores de matemática. Isso se considerarmos, por exemplo, que o tratamento da dimensão histórica nessa formação ganhou força em 2001, quando os cursos de licenciatura em matemática, com o advento das Diretrizes Curriculares Nacionais para os Cursos de Matemática, Bacharelado e Licenciatura, Parecer CNE 1302/2001 (BRASIL, 2001), tiveram que implementar em seus projetos pedagógicos, conteúdos curriculares que, em sua base comum, exigiam a inclusão dos "conteúdos da Ciência da Educação, da História e Filosofia das Ciências e da Matemática" (BRASIL, 2001, p. 6).

Como, então, tratar da dimensão história, ou mais particularmente da história da educação matemática no curso de licenciatura em matemática, sob o enfoque de metodologia formativa do futuro professor?

\begin{abstract}
A resposta parece apontar para a criação de situações que coloquem o futuro docente na discussão histórico-epistemológica da constituição da matemática escolar. A organização dos programas, dos currículos, do significado daquilo que se ensina e a justificativa do seu ensino, em termos do que estamos considerando matemática escolar, tem uma história. Dessa maneira, o licenciando necessita apossar-se da História da educação matemática como ingrediente fundamental para exercício da futura profissão (VALENTE, 2012, p. 7, grifo do autor).
\end{abstract}

Desse modo, a questão que se apresenta, considerando a dimensão histórica na formação de professores de matemática, está relacionada a uma postura históricoepistemológica que poderá contribuir para a reelaboração de práticas pedagógicas do professor de matemática à medida que este compreender que seu trabalho docente implica a condução de uma disciplina escolar, a matemática, que foi historicamente constituída, ao longo dos anos.

\section{ESTUDO DO ARTIGO "QUEM SOMOS NÓS PROFESSORES DE MATEMÁTICA?"}

Partindo da premissa que considerar a dimensão histórica favorece uma visão diferente do sentido da prática pedagógica na atualidade, dado que a profissão professor de 


\section{REVISTA REAMEC}

Revista da Rede Amazônica de Educação

em Ciências e Matemática

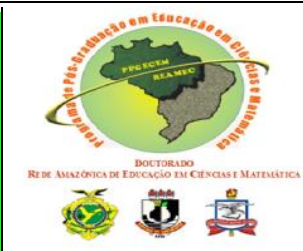

matemática é herdeira de práticas que vêm de diferentes épocas, Valente (2008) faz uma breve genealogia de alguns antepassados profissionais dos professores de matemática, centrando-se naqueles professores que estão, nos dias atuais, voltados para os Ensinos Fundamental ( $6^{\circ}$ ao $9^{\circ}$ ano) e Médio. Nessa genealogia, menciona os seguintes antepassados: tataravô, bisavô, avô e pai profissional. Vejamos, resumidamente, sobre cada um.

Diz-nos o autor que o tataravô profissional do professor de matemática viveu no século XVIII, e retirou da guerra, da necessidade de proteção, o sentido de seu ofício. Esse tataravô pode ser bem representado pelo militar português José Fernandes Pinto Alpoim que, de 1738 a 1765, ministrou Aula de Artilharia e Fortificações para militares brasileiros.

Ressalta que a necessidade de criação de Aula de Artilharia e Fortificações surgiu no final do século XVII em um momento em que o Brasil, ainda colônia de Portugal, estava ameaçado, por todos os lados (pelo menos assim era visto pela Coroa Portuguesa), de ser saqueado em suas riquezas naturais. Então, preocupada em defender a Colônia, a Coroa Portuguesa vislumbrara a necessidade de formar militares bem treinados, com habilidade de manusear artilharia e construir fortes. Com esse objetivo, foi criada a Aula de Artilharia e Fortificações, cujo material didático disponível eram volumosos tomos, que tinham como conteúdo um curso de matemática, seguido de instruções de manuseio de armas. A Aula de Artilharia e Fortificações tornou-se obrigatória a todo militar, pois dependia de aprovação para ser promovido ou nomeado.

O autor informa que Alpoim escreveu os dois primeiros livros didáticos de matemática do Brasil: Exame de artilheiros, em 1744, e Exame de bombeiros, em 1748. Se recuarmos no tempo e entrarmos na sala de aula desse nosso tataravô profissional, vamos encontrá-lo com um grupo de alunos, em torno de quinze, anotando parte de sua obra didática, que a partir da geometria, ensinava como é possível calcular o número de balas de canhão que pode conter em um determinado lugar, ou ainda, saber quantas balas cabe em uma pilha de balas de canhão, conforme figura 1 .

Figura 1 - Página do livro Exame de artilheiros 


\section{REVISTA REAMEC}

Revista da Rede Amazônica de Educação

em Ciências e Matemática
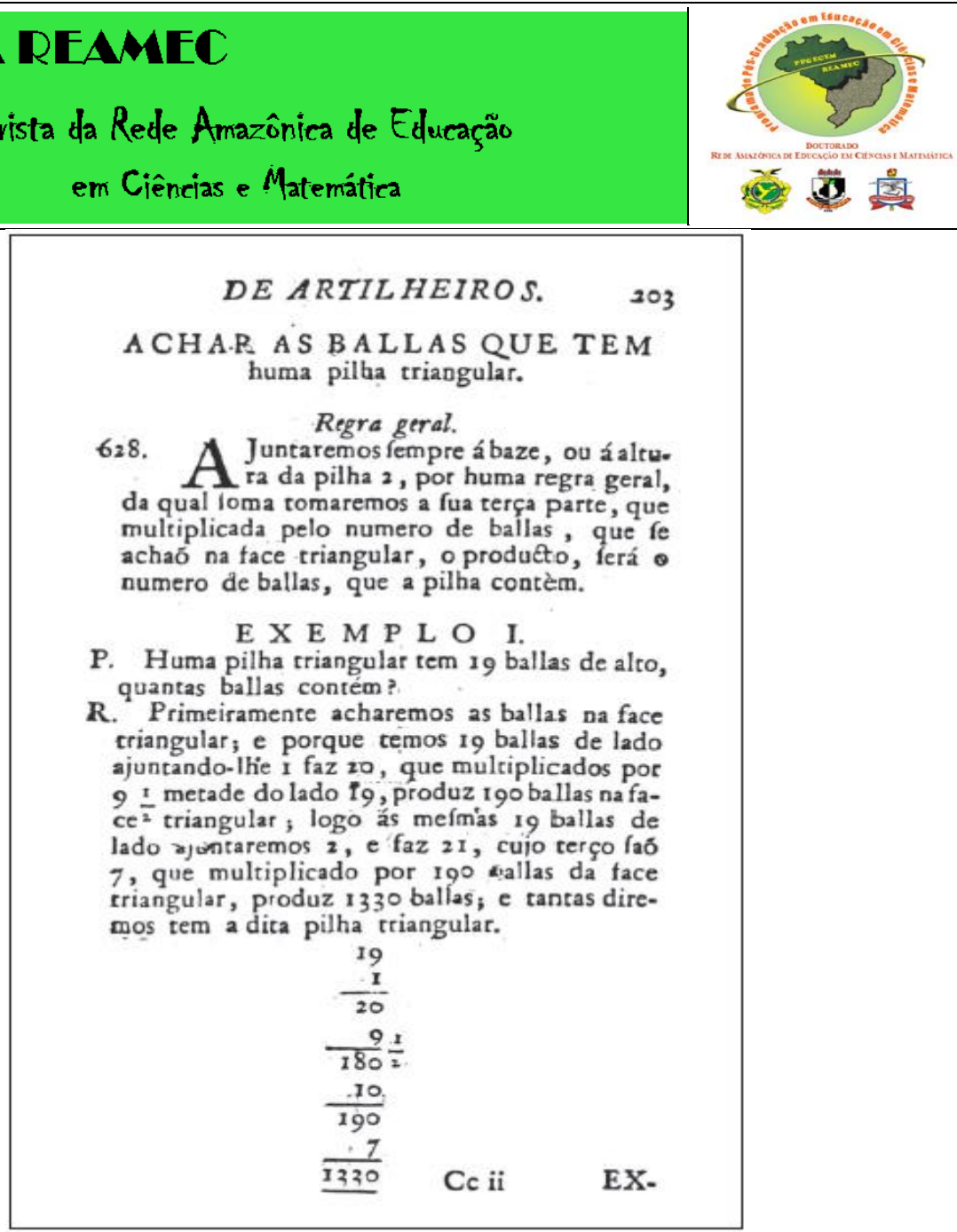

Página | 10

Fonte: Alpoim (1744 apud VALENTE, 2008, p. 14)

Como vimos, esse nosso tataravô professor de matemática, praticava seu magistério ditando curso para os alunos copiarem, o que justificava o ensino de elementos de geometria e aritmética, pois eram conteúdos matemáticos dos livros de nosso tataravô profissional, legado transmitido a seu filho, nosso bisavô profissional.

No entanto, argumenta o autor que nosso bisavô profissional viu o sentido de seu magistério como professor de matemática de aulas avulsas, gênese dos cursos preparatórios, pois quando se deu conta de seu ofício estava preparando aulas de geometria para cursinhos preparatórios de ingressos em cursos jurídicos. Isso ocorreu porque, com a independência do Brasil, fez-se necessária a criação de uma universidade no país que formasse aqui a elite brasileira, sendo criados, então, os cursos jurídicos, na primeira metade do século XIX. Com a criação desses cursos, surgiu a necessidade de preparação para exame de ingresso, tendo dentre as provas de exame, além de língua francesa, gramática latina, retórica, filosofia racional e moral, a entrada da geometria. Isso fez com que a matemática mudasse oficialmente de status, passando de conteúdos de caráter técnico-instrumental a conteúdos 


\section{REVISTA REAMEC}

Revista da Rede Amazônica de Educação

em Ciências e Matemática

matemáticos, vistos como categoria de saber de cultura geral, como os demais conteúdos do exame.

O autor comenta, ainda, que definidas as condições de ingresso aos cursos jurídicos, por toda parte, aulas avulsas passaram a constituir o embrião de cursos preparatórios, a quem Página | 11 caberia a preparação dos candidatos ao ensino superior. Embora a existência de vários projetos que acenavam com a obrigatoriedade do diploma do secundário seriado para ingresso nas faculdades, via de regra, no século XIX, os alunos estudavam as disciplinas dos preparatórios e, ao cabo dos exames, abandonavam a instituição com os exames parcialmente realizados, rumo à matrícula no ensino superior. O ensino secundário seriado não se difundia. O caminho dos preparatórios era muito mais rápido do que o da seriação escolar secundária. Preparar-se para o ensino superior, para o ingresso nas faculdades, representava estudar os pontos dos exames. Esses pontos além de organizar, por exemplo, toda a matemática escolar e seu ensino, eram referência também para a elaboração da literatura escolar, a exemplo do texto de Jeronimo Pereira Lima, intitulado Pontos de Geometria para provas escritas nos exames da instrução pública da Corte.

Nessa perspectiva, em conformidade com o autor, o ofício maior de nosso bisavô profissional consistia em fazer com que seus alunos fixassem os pontos. Estes eram organizados de modo que, após o enunciado ponto, seguiam as recomendações do autor sobre quantas definições, aplicações e teoremas eram necessários decorar. Em seguida, vinha o texto sintético, pronto para ser decorado. Com a lista dos pontos, o candidato preparava-se para as provas escritas e orais, que deveriam saber de cor para ser bem sucedido no ingresso no ensino superior. Um a um, os exames deveriam ser eliminados; a cada um deles, um certificado. De posse do conjunto de certificados, que atestavam a conclusão das disciplinas, o candidato ganhava o direito de matrícula no ensino superior. Esse sistema permaneceu e sedimentou a prática de nosso bisavô profissional: fazer com que os alunos decorassem, ou seja, fixassem os pontos de matemática para ingresso no ensino superior. Tal sistema existiu por cerca de 100 anos, cruzando o Império e as primeiras décadas da República, sendo alcançado pelo filho de nosso bisavô, o nosso avô profissional.

Não obstante, diz o autor, o nosso avô profissional viu, ainda na primeira metade do século XX, por volta de 1930, os cursinhos preparatórios irem desaparecendo para dar lugar à implantação do sistema seriado de ensino. No entanto, o fato mais marcante dos 


\section{REVISTA REAMEC}

\section{Revista da Rede Amazônica de Educação \\ em Ciências e Matemática}

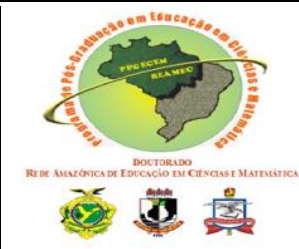

antepassados profissionais do professor de matemática foi presenciado por seu avô profissional, como resultado da fusão da aritmética, com a álgebra e a geometria: o nascimento Matemática como uma nova disciplina escolar.

Para Valente (2008), dentre os vários questionamentos que surgiram, um se destacou Página | 12 focado na prática dos professores de matemática: como fazer para ensinar matemática como fusão de geometria, álgebra e aritmética? Propostas revolucionárias surgiram, mas nosso avô preferiu seguir a herança de seus antepassados de profissão: dividiu as aulas semanais em partes separadas, de modo que, por exemplo, na segunda-feira fosse lecionada aritmética; na terça, álgebra; na quarta geometria, como evidenciado na própria organização de um dos livros didáticos mais vendidos no tempo de nosso avô profissional, conforme figura abaixo:

Figura 2 - Parte do índice do livro "Matemática - primeiro ano ginasial"

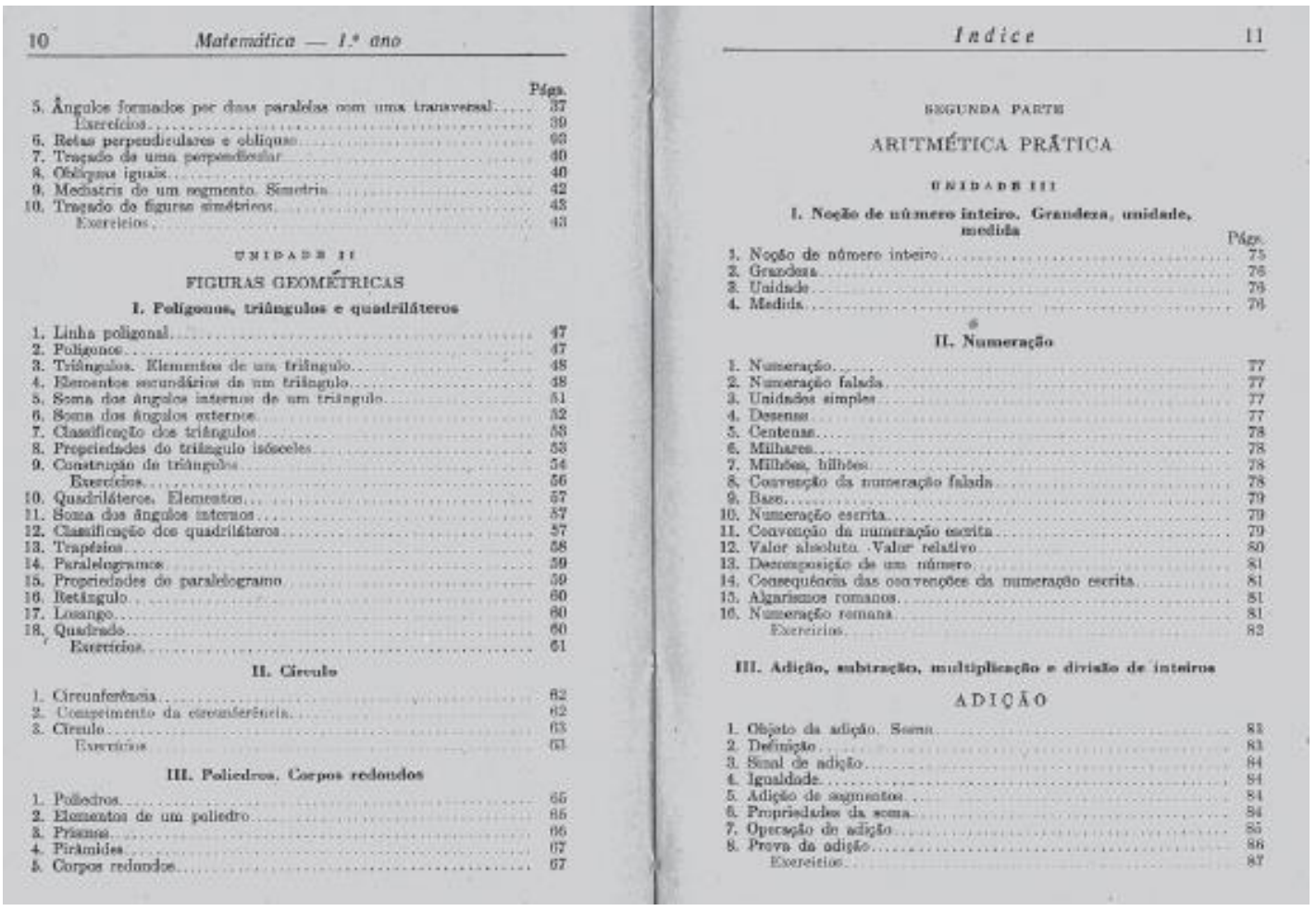

Fonte: Quintella (1940 apud VALENTE, 2008, p. 20).

Portanto, como seus antepassados profissionais, a prática de nosso avô, professor de matemática estava ainda centrada no ponto, a essa altura chamado de unidade, na fixação de conteúdos, um drama ainda vivido por seu filho, nosso pai profissional, já na segunda metade do século XX.

No sentido apontado pelo autor, entretanto, nosso pai profissional vivia um drama ainda maior, que tem início na década de 1960, pois lhe era cobrado que esquecesse a herança Revista REAMEC, Cuiabá - MT, n.01, setembro 2013, ISSN: 


\section{REVISTA REAMEC}

Revista da Rede Amazônica de Educação

em Ciências e Matemática

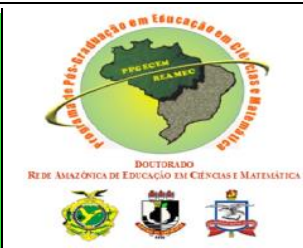

de seu tataravô, bisavô e avô e ensinasse a matemática moderna. Para tanto, esse professor precisava de uma preparação, o que lhe era oferecido por convites para participar de cursos de treinamento, além dos novos livros didáticos que surgiam. O primeiro desses livros

[...] passa a ser utilizado por todo o Brasil e, também, por nosso parente de Página | 13 profissão: o livro de Osvaldo Sangiorgi. Lançado em 1963, o primeiro de uma série de quatro, faz escola entre os professores e constitui guia para o trabalho de ensinar a matemática moderna. Em cena, nas aulas, os conjuntos, as estruturas algébricas. Acompanha cada exemplar um 'Guia para uso dos professores' (VALENTE, 2008, p. 21).

Sendo assim, tudo era exposto a nosso pai professor de matemática como inovação, era necessário reaprender uma nova matemática: a matemática moderna. Porém, as expectativas para essa nova matemática com métodos novos de ensino inovadores parece ter frustrado esse nosso antepassado mais próximo, pai de profissão. Tanto que nós, seus filhos, professores atuais de matemática, que desde o final do século XX e já percorrido uma década do século XXI, parecemos ter herdado algo dessa frustração.

Todavia, partindo do ponto que considerar nossa herança histórica de professor de matemática favorece uma visão diferente do sentido da prática pedagógica na atualidade, como isso pode realmente se efetivar na formação de professores de hoje, considerando a trajetória desses nossos antepassados?

As considerações do autor parecem bastante apropriadas para responder a essa questão, quando possibilitam a compreensão de que considerar a dimensão histórica na formação de professores de matemática pode remeter a um campo complexo, permeado de intencionalidades e significados que tendem a interferir naquela formação.

\section{ANÁLISE CRÍTICA DO ARTIGO}

Para proceder à análise crítica, fazemos uso do esquema paradigmático proposto por Gamboa (2007), que surge, segundo esse autor, da necessidade de estudar a qualidade das produções científicas, que vem aumentando a cada dia.

O objetivo do esquema paradigmático é buscar relações lógicas entre os elementos constitutivos dos conhecimentos produzidos. Essa produção de conhecimento

[...] se dá em todo processo de investigação e se supõe que 'todo processo de produção de conhecimento é a manifestação de uma estrutura de pensamento que inclui conteúdos filosóficos, lógicos, epistemológicos, teóricos, metodológicos e 


\section{REVISTA REAMEC}

Revista da Rede Amazônica de Eduração

em Ciências e Matemática

técnicos que implicam sempre modos de atuar e omitir' (BENGOECHEA, 1978 apud GAMBOA, 2007, p. 36).

Em outras palavras, podemos dizer que o que se busca com o uso do esquema paradigmático são as relações lógicas do texto analisado para a solução do problema proposto. Estamos entendendo que aquilo que pode ser evidenciado (ou não) na busca por essas relações lógicas, em determinado texto analisado, pode constituir uma análise crítica.

Na visão de Gamboa (2007), o esquema paradigmático permite reconstituir a lógica do texto no trajeto percorrido na investigação que vai da Pergunta (P) até a Resposta (R). Adota a análise da pergunta que orientou o estudo, como ponto de partida, e a elaboração da resposta, como ponto de chegada. Para a elaboração da resposta, propõe categorias em seis níveis diferentes de complexidades, a saber: nível técnico - tipo de operacionalização para chegar à coleta e à sistematização das informações; nível metodológico - modos como são organizados os processos de conhecimento; nível teórico - núcleo conceitual básico utilizado na abordagem do fenômeno estudado; pressupostos epistemológicos - concepções de causalidade, de ciência e critérios de validação do estudo; pressupostos gnosiológicos maneiras de conceber o objeto e relacioná-lo com o sujeito no processo cognitivo; pressupostos ontológicos - visão do pesquisador em torno do problema/fenômeno estudado, no processo de elaborar perguntas e procurar respostas.

Vejamos como esse trajeto se deu no artigo em análise.

A construção da pergunta - Valente (2008) faz três indagações que vão permitir, $a$ posteriori, sustentar seu argumento de que o ofício de ser professor de matemática é herdeiro de práticas e saberes que vêm de diferentes épocas. Essas indagações vêm da necessidade de se pensar o processo ensino-aprendizagem da matemática e as práticas pedagógicas dos professores. O autor questiona: Por que ensinamos o que ensinamos aos nossos alunos e da maneira como ensinamos? Por que valorizamos determinadas práticas e não outras? Quem somos nós, professores de matemática? O que se pode depreender é que a questão central é esta última, que dá título ao texto. As duas questões anteriores são norteadoras, são aquelas que, trilhadas, poderão responder à indagação central.

A construção da resposta - para construir a resposta, Valente (2008) organiza seu estudo em quatro momentos que se articulam, a modo de uma genealogia profissional do professor de matemática, quanto ao seu tataravô, bisavô, avô e pai profissional. 


\section{REVISTA REAMEC}

Revista da Rede Amazônica de Educação

em Ciências e Matemática

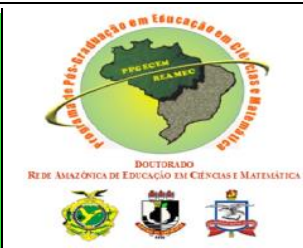

- Nível técnico e metodológico - o autor fez um estudo de cunho qualitativo, em que pudemos inferir que fez uso da perspectiva histórico-cultural, embora não declarada, mas manifesta, na medida em que nos foi possível apreender que os tempos vividos por cada antepassado do professor de matemática eram espaços de conflitos, onde se estabeleciam relações de poder. Para tanto, fez uso da análise de fontes históricas, "análise de objetos culturais" (VALENTE, 2007), como exemplo, páginas de obras utilizadas para ensinar matemática nos anos de 1744, 1869, 1940 e 1963, tendo em conta que um estudo de cunho histórico "envolve a formulação de questões aos traços deixados pelo passado, que são conduzidos à posição de fontes de pesquisa por essas questões, com o fim da construção de fatos históricos, representados pelas respostas a elas" (VALENTE, 2007, p. 32).

- Nível teórico - de acordo com Gamboa (2007), as referências teóricas podem assegurar mais informações para as análises contextualizadas a partir de um prévio referencial teórico. Não discordamos disso, mas em pesquisas educacionais, ainda mais de caráter histórico, concordamos com Valente (2007) que, por vezes, não é necessário nem possível separar o corpo teórico da questão da metodologia da pesquisa, pois ainda segundo o autor, um fato histórico é constituído a partir de indícios deixados no presente pelo passado, cabendo ao historiador efetuar um trabalho sobre esses indícios para construir os fatos, que são, então, resultados de uma elaboração a partir das marcas do passado. Foi o que fez o autor, no texto analisado. Utilizou as marcas, fontes históricas, para as análises contextualizadas e, sobretudo, para dar vida aos antepassados, principalmente aqueles mais remotos, do professor de matemática.

- Nível epistemológico - o autor centrou a construção do conhecimento nas relações entre o ser humano (na figura do tataravô, bisavô, avô e pai profissional do professor de matemática) e seu contexto mais próximo (a realidade do contexto educacional brasileiro em que viviam), na razão em que focalizou o objeto particular de análise (quem somos nós professores de matemática) sem a intenção de elaborar generalizações. Nesse sentido, o autor procura entender problemas que vivenciamos hoje como professores de matemática, a partir da relação com nossos antepassados profissionais.

- Pressupostos gnosiológicos - o autor concebe o conhecimento como histórico, não linear, deixando entrever, na existência de saberes gerados na prática pedagógica de nossos antepassados profissionais, a resistência ao novo. Isso é visível ao tratar de nosso avô 


\section{REVISTA REAMEC}

Revista da Rede Amazônica de Educação

em Ciências e Matemática

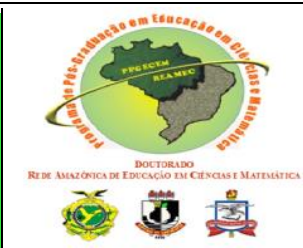

profissional, quando este teve de ensinar matemática, como disciplina escolar nascida da fusão da aritmética, com a álgebra e a geometria, e se viu perante o dilema de como promover um ensino de matemática, considerando essa fusão. Nesse aspecto, explica o autor que, embora as propostas revolucionárias que surgiram, nosso avô preferiu seguir a herança de seus antepassados de profissão: dividiu as aulas semanais em partes separadas, ou seja, continuou a ensinar separadamente a aritmética, a álgebra e a geometria. Podemos ver nesse movimento uma situação histórica concreta e particular, a cultura escolar como uma forma de expressar valores construídos. Nisso, o autor, ao mostrar sinais da cultura escolar, evidencia formas de como os professores de matemática se apropriavam das culturas em que estavam imersos, nos diversos momentos da história de escolarização, e também de sua formação profissional.

- Pressupostos ontológicos - o autor destaca que conhecer sua genealogia profissional pode contribuir para o melhor conhecimento de si mesmo como profissional. Nesse caso, refere-se ao trabalho do professor de matemática, mostrando sinais que ao saber quem são seus avôs, bisavôs e mesmo tataravôs profissionais, o professor de matemática tem mais possibilidade de ver o seu próprio fazer docente de outro modo e dar a ele uma dimensão histórica. Enfatiza que, ao considerar seu trabalho numa dimensão histórica, o professor de matemática pode ter uma compreensão diferente do sentido das ações realizadas nas salas de aula hoje. Com isso, defende que, ao ter ciência de contextos de outros tempos, o professor de matemática tem melhores condições de entendimento do que são novidades e continuidades, na tarefa cotidiana de ensinar matemática.

\section{CONSIDERAÇÕES FINAIS}

A análise crítica do artigo de Valente (2008), que procurou responder ao questionamento "quem somos nós professores de matemática?", com o argumento de que a dimensão histórica, na perspectiva de metodologia formativa, é necessária para que esses professores produzam novos saberes e criem novas práticas capazes de possibilitar um ensino de matemática com melhor qualidade, trouxe-nos condições efetivas de compreender a importância dessa dimensão na formação de professores em geral, e de matemática em particular. 
O autor foi conciso, mas ao mesmo tempo denso, quando mostrou, a partir de fontes históricas, que a formação profissional de nosso avô foi bastante diferente daquela do tataravô e bisavô professores de matemática. Enquanto estes vieram dos cursos militares, das escolas de engenharia, aquele teve nas faculdades de filosofia seu berço profissional. Com isso, permitiu-nos perceber que essa formação foi diferente da de nosso pai profissional, que na década de 1970 viu surgir uma nova modalidade de licenciatura, denominada licenciatura curta $^{6}$, regulamentada pela Resolução CFE $n^{0}$ 30/74 (BRASIL, 1974), que facultou às Instituições de Ensino Superior oferecer cursos de curta duração, como também de licenciatura plena. Nosso pai profissional ainda teve tempo de ver a atual formação de professores de matemática, que por força da Lei 9394/96, Lei de Diretrizes e Bases da Educação Nacional (BRASIL, 1996), estabeleceu que a formação de professores de matemática para atuar na Educação Básica (Ensinos Fundamental II e Médio) deve ser realizada em nível superior, em curso de licenciatura, de graduação plena, em universidades e institutos superiores de educação.

Foi possível observar que esse olhar histórico para a formação de professores está ganhando espaço nos debates teóricos e na consolidação das linhas de pesquisa dos cursos de pós-graduação no Brasil. Isso tem alavancado as discussões sobre as mudanças ocorridas nas práticas pedagógicas dos professores condicionadas, entre outras, pelas restrições ligadas às condições de trabalho, pela ausência de políticas educacionais efetivas e pelas próprias condições formativas do professor em cada época.

Particularmente, quanto aos professores de matemática, o artigo analisado, à medida que possibilitou refletir sobre algumas práticas profissionais de nossos antepassados, permitiu-nos ter um olhar retrospectivo para vermos hoje que os tempos de ditar curso passaram, mas ficaram os de ditar ou escrever exercícios a serem resolvidos pelos alunos, em que se trocou a lição pelo exercício. A primeira, a lição, era a escrita da aula dada pelo professor, e aprender matemática significava memorizar, passar a limpo a lição. O segundo era passar exercícios para os alunos resolver de modo correto, o que significava aprendizagem da matemática. Esta prática, o professor de matemática nunca mais abandonou, continua viva em pleno século XXI.

\footnotetext{
${ }^{6}$ De acordo com Candau (1987), os cursos de curta duração não são uma novidade, pois já haviam sido criados nos anos 60 com a finalidade de formar professores para a escola média. No entanto, seu caráter era emergencial, enquanto os cursos criados nos anos 70 surgiram como processo regular de formação de professores. 


\section{REVISTA REAMEC}

Revista da Rede Amazônica de Educação

em Ciências e Matemática

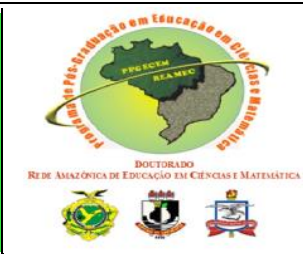

No entanto, o autor, com muita propriedade, convida-nos a voltar o olhar para os nossos antepassados e procurar refletir por que essa prática ainda permanece. E nessa reflexão, impulsiona-nos a abrir novos caminhos na expectativa de melhor utilizar a herança que nossos parentes profissionais deixaram, construindo novas práticas e saberes com esse legado. Vemos que talvez essa seja uma das principais contribuições que advêm de se considerar a dimensão histórica na formação de professores de matemática.

Essa questão parece ser bastante significativa e nos levou a algumas reflexões que, em nosso entendimento, merecem uma abordagem, embora breve, a título de considerações finais. Se levarmos em conta, por exemplo, as propostas atuais em busca de um ensino de matemática que contribua para a formação de um aluno mais participativo, reflexivo e autônomo, que se intensificaram na década de 90, mais precisamente com promulgação da Lei 9394/96 - Lei de Diretrizes e Bases da Educação Nacional (BRASIL, 1996), vamos perceber uma profunda ressignificação do processo de ensinar e aprender e a prescrição de um paradigma curricular em que os conteúdos de ensino deixam de ter importância em si mesmos e passam a ser entendidos como meio para produzir aprendizagem dos alunos (MELLO, 2000).

Procurando implementar o novo paradigma curricular, em 1998, o Ministério da Educação (MEC) disponibilizou, em caráter de recomendação, a todos os sistemas de ensino e escolas, os Parâmetros Curriculares Nacionais para o Ensino Fundamental. Os parâmetros para o Ensino de Matemática sugerem que a matemática seja caracterizada "como uma forma de compreender e atuar no mundo e o conhecimento gerado nessa área do saber como um fruto da construção humana na sua interação constante com o contexto natural, social e cultural" (BRASIL, 1998, p. 24).

Vemos que essa visão opõe-se àquela vivida por nossos antepassados mais distantes, que considerava a Matemática como um corpo de conhecimento imutável e verdadeiro a ser assimilado pelo aluno. Com isso, os objetivos do ensino da matemática de fazer o aluno memorizar, decorar, copiar, passar a limpo, etc (VALENTE, 2010) são substituídos por objetivos como ampliar, construir identificar, interpretar, selecionar, estabelecer e resolver problemas (BRASIL, 1998). 


\section{REVISTA REAMEC}

Revista da Rede Amazônica de Educação

em Ciências e Matemática

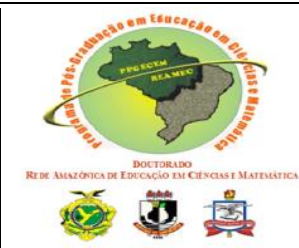

Neste terceiro milênio, mais aclamada tem sido a urgência de incorporar, no ensino de matemática, discussões relacionadas aos avanços propiciados pelas Tecnologias da Informação e da Comunicação, a exemplo, computador e a internet, que vêm provocando mudanças radicais em todos os setores da sociedade e, particularmente, no espaço da sala de aula. Uma dessas mudanças diz respeito ao tratamento, ainda tradicional, dado aos conteúdos de ensino, o que tem produzido acirradas discussões em relação à formação de professores, para lidar com as novas exigências da sociedade da informação e da comunicação, em busca da formação de um estudante crítico e participativo, na construção de uma sociedade mais humana.

Esse movimento guarda forte relação com aquele vivido pelo nosso pai profissional na década de 1960, período em que nosso país viveu o movimento de modernização do ensino conhecido com Movimento da Matemática Moderna, que visava a adaptar a disciplina escolar às aspirações e necessidades do mundo moderno.

Percebemos ao longo desses anos que, embora as preocupações com o ensino e a aprendizagem da matemática, bem como os avanços nas pesquisas nessa área, as inovações pretendidas foram muito mais discutidas do que verdadeiramente incorporadas à prática pedagógica dos professores, o que vem causando acirradas discussões, particularmente a respeito da formação de professores de matemática.

Em face do exposto concordamos com Valente (2008, p. 12):

As preocupações com o ensino e aprendizagem da matemática, tão fortemente ligadas ao presente e às projeções para o futuro, tão ciosas daquilo que realmente interessaria ensinar e aprender, de modo que a matemática faça sentido hoje e amanhã aos alunos, têm descuidado da dimensão histórica. Esse descuido, não raro, faz subtrair à análise e às propostas de transformação as heranças que todos os ofícios carregam consigo. Sem ter presente essa dimensão histórica, os projetos de melhoria do ensino de matemática tendem ao fracasso.

Da mesma forma, podemos inferir que, em relação à formação de professores de matemática, há problemas antigos e novos a ser enfrentados e discutidos, tarefa que requer a presença da dimensão histórica para que não se afirme, ingenuamente, expressões do tipo "hoje vivemos a pior fase do ensino da matemática, bom era o ensino que tiveram os nossos bisavós, avós ou mesmos pais", como ainda se houve. À dimensão histórica cabe

[...] criticar essas representações do passado, que têm fundo ficcional, memorialístico e a-histórico. Desconstruir essas representações de outros tempos da educação matemática, alterar a relação que os professores de matemática têm com os 


\section{REVISTA REAMEC}

Revista da Rede Amazônica de Educação

em Ciências e Matemática

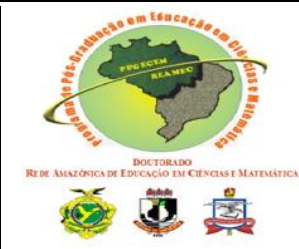

seus antepassados profissionais, em benefício de novas representações mais alicerçadas na crítica aos documentos e fontes das práticas pedagógicas realizadas noutros tempos é tarefa que justifica a inclusão da história da educação matemática na formação de professores (VALENTE, 2010, p. 134).

Além do mais, a dimensão histórica na formação do professor de matemática suscita a valorização do contexto e da realidade em que essa formação se dá, revelando a necessidade de não se ficar aquém ou além dessa realidade, mas vivê-la no presente sem subtrair à análise e às propostas de transformação os legados que nossos tataravôs, bisavôs, avôs e pais, antepassados profissionais presentes em todas as profissões (ou quase todas), carregam consigo.

Por fim, vale destacar que, pela relevância do tema, pela clareza na construção das ideias e pela coerência lógica na argumentação desenvolvida, recomenda-se a leitura do artigo analisado, além de reconhecer sua grande relevância para todos aqueles que, como o autor, entendem (ou querem entender) a dimensão histórica na formação de professores de matemática, como metodologia formativa. Esse entendimento pode remeter a um campo complexo, permeado de intencionalidades e significados que possibilitem uma compreensão mais ampla daquela formação.

Recebido $1^{\text {a }}$ versão: 05 de junho de 2013 - Recebido $2^{\text {a }}$ versão: 15 de julho de 2013 Aceito: 10 de setembro de 2013

Publicado: 20 de setembro de 2013

\section{REFERÊNCIAS}

BRASIL. Conselho Federal de Educação. Fixa o currículo mínimo e a duração do curso de licenciatura em Ciências com habilitações. Resolução CFE 30/74. Brasília- DF, 1974.

BRASIL. Conselho Nacional de Educação. Diretrizes Curriculares Nacionais para os Cursos de Matemática, Bacharelado e Licenciatura. Parecer CNE/CES 1302/2001. Brasília: CNE, 2001.

BRASIL. Lei de Diretrizes e Bases da Educação Nacional. Lei no 9394, de 20 de dezembro de 1996. Brasília, 1996.

BRASIL. Secretaria de Educação Fundamental. Parâmetros curriculares nacionais: Matemática. Brasília: MEC /SEF, 1998.

BRZEZINSK, I.; GARRIDO, E. Trabalho docente: mapeando a pesquisa em teses e dissertações brasileiras. Educação \& Linguagem, ano 10, n. 15, p. 60-81, 2007.

CANDAU, V. M. Novos rumos da licenciatura. Brasília: INEP, 1987. 


\section{REVISTA REAMEC}

Revista da Rede Amazônica de Eduração

em Ciências e Matemática

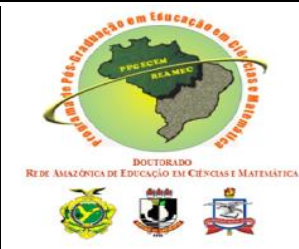

GAMBOA, Silvio Sanches. Pesquisa em educação: métodos e epistemologias. Chapecó: Argos, 2007.

GROENWALD, C. et al. Perspectivas em Educação Matemática. Acta Scientiae, Canoas, v.6, n.1, p.37-55, jan/jun. 2004.

MELLO, G. N. de. Formação inicial de professores para a educação básica: uma (re)visão radical. São Paulo em perspectiva, São Paulo, v. 14, n.1, p. 1-23, 2000.

SOUTO, R. M. A. História na Educação Matemática: um estudo sobre trabalhos publicados no Brasil nos últimos cinco anos. Bolema, Rio Claro (SP), v. 23, nº 35B, p. 515 a 536, abril 2010

VALENTE, R. W. O lugar da matemática escolar na licenciatura em matemática. REUNIÃO ANUAL DA ANPEd, 35, 2012, Pernambuco. Trabalho encomendado - GT 19. Disponível em: 〈http://www.anped.org.br/app/webroot/files/35ANPED_TE_Valente(1).pdf $>$. Acesso em 28 dez. 2012.

VALENTE, R. W. História da educação matemática: considerações sobre suas potencialidades na formação do professor de matemática. Bolema, Rio Claro (SP), v. 23, n. 35A, p. 123 -136, abr. 2010.

VALENTE, R. W. Quem somos nós, professores de matemática? Cad. Cedes, Campinas, v. 28, n. 74, p. 11-23, jan./abr. 2008.

VALENTE, W. R. História da Educação Matemática: interrogações metodológicas. REVEMAT, UFSC, v. 2.2, p. $28-49,2007$. 